\title{
Uncertainty Reduction of Arctic Sea Ice Freeboard from CryoSat-2 Interferometric Mode
}

Di Bella, A.; Skourup, H.; Bouffard, J.; Parrinello, T.

Published in:

Advances in Space Research

Link to article, DOI:

10.1016/j.asr.2018.03.018

Publication date:

2018

Document Version

Peer reviewed version

Link back to DTU Orbit

Citation (APA):

Di Bella, A., Skourup, H., Bouffard, J., \& Parrinello, T. (2018). Uncertainty Reduction of Arctic Sea Ice Freeboard from CryoSat-2 Interferometric Mode. Advances in Space Research, 62(6), 1251-1264.

https://doi.org/10.1016/j.asr.2018.03.018

\section{General rights}

Copyright and moral rights for the publications made accessible in the public portal are retained by the authors and/or other copyright owners and it is a condition of accessing publications that users recognise and abide by the legal requirements associated with these rights.

- Users may download and print one copy of any publication from the public portal for the purpose of private study or research.

- You may not further distribute the material or use it for any profit-making activity or commercial gain

- You may freely distribute the URL identifying the publication in the public portal

If you believe that this document breaches copyright please contact us providing details, and we will remove access to the work immediately and investigate your claim 


\section{Accepted Manuscript}

Uncertainty Reduction of Arctic Sea Ice Freeboard from CryoSat-2 Interferometric Mode

A. Di Bella, H. Skourup, J. Bouffard, T. Parrinello

PII:

S0273-1177(18)30221-7

DOI:

https://doi.org/10.1016/j.asr.2018.03.018

Reference:

JASR 13677

To appear in:

Advances in Space Research

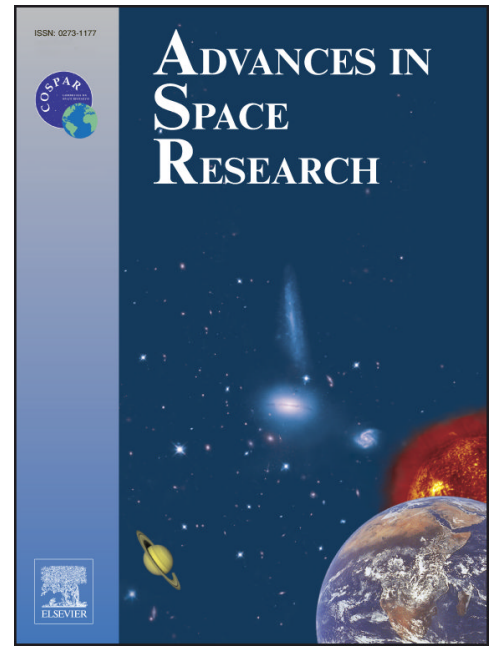

Accepted Date: $\quad 9$ March 2018

Please cite this article as: Di Bella, A., Skourup, H., Bouffard, J., Parrinello, T., Uncertainty Reduction of Arctic Sea Ice Freeboard from CryoSat-2 Interferometric Mode, Advances in Space Research (2018), doi: https://doi.org/ 10.1016/j.asr.2018.03.018

This is a PDF file of an unedited manuscript that has been accepted for publication. As a service to our customers we are providing this early version of the manuscript. The manuscript will undergo copyediting, typesetting, and review of the resulting proof before it is published in its final form. Please note that during the production process errors may be discovered which could affect the content, and all legal disclaimers that apply to the journal pertain. 


\title{
Uncertainty Reduction of Arctic Sea Ice Freeboard from CryoSat-2 Interferometric Mode
}

\author{
A. Di Bella ${ }^{1}$ \\ DTU Space, National Space Institute, Elektrovej 327, 2800 Kgs. Lyngby, Denmark \\ H. Skourup, J. Bouffard \\ DTU Space, National Space Institute, Elektrovej 327, 2800 Kgs. Lyngby, Denmark \\ ESA/ESRIN, Via Galileo Galilei C.P. 64, 00044 Frascati, Italy
}

T. Parrinello

ESA/ESRIN, Via Galileo Galilei C.P. 64, 00044 Frascati, Italy

\begin{abstract}
A study by Armitage and Davidson (2014) has shown that the extra information from the CryoSat-2 (CS2) SARIn mode increases the number of valid sea surface height estimates which are usually discarded in the SAR mode due to snagging of the radar signal. As the number of valid detected leads increases, the uncertainty of the freeboard heights decreases.

In this study, the freeboard heights estimated by processing CS2 SARIn level $1 \mathrm{~b}$ waveforms are validated using the information from airborne laser and radar altimetry as well as snow radar measurements acquired during the CryoVEx 2012 and Operation IceBridge 2012 campaigns, respectively. The possible reduction in the random freeboard uncertainty is investigated comparing two scenarios, i.e. a SAR-like and a SARIn acquisition.

A very good agreement is found between average airborne and satellite radar freeboards although, at the CS2 footprint scale, they do not show along-track spatial correlation. It is observed that using the extra phase information, CS2 is able to detect leads up to $2300 \mathrm{~m}$ off-nadir. A reduction in the the total

Email addresses: adia@space.dtu.dk (A. Di Bella), hsk@space.dtu.dk, jerome.bouffard@esa.int (H. Skourup, J. Bouffard), tommaso.parrinello@esa.int (T. Parrinello)

${ }^{1}$ Corresponding author
\end{abstract}


random freeboard uncertainty of $\sim 40 \%$ is observed by taking advantage of the CS2 interferometric capabilities, which enable to include $\sim 35 \%$ of the waveforms discarded in the SAR-like scenario.

Keywords: CryoSat-2; Sea ice; freeboard; uncertainty; SARIn; altimetry

\section{Introduction}

Sea ice is one of the most significant climate parameters interacting with several feedback processes of the global climate system. Changes in the sea ice cover represent one of the most visible components of climate change influencing directly the albedo of our planet. Furthermore, variations in the ice volume reflect changes in the heat budget of the Arctic (Laxon et al., 2013) and can influence the climate at a global scale.

Remote sensing records of Arctic sea ice now span over several decades. Satellite observations show a rapid reduction of the ice-covered area in the Arctic (Comiso, 2012) especially during summers (Stroeve et al., 2012) which, together with evidences about the thinning of Arctic sea ice (Kwok and Rothrock, 2009), may cause a reduction of the sea ice volume at an even faster rate than observed for sea ice extent (Desch et al., 2017). Estimating the sea ice volume from satellite observations requires the knowledge of the sea ice extent and thickness. While the extent can be measured directly by satellites, the estimation of the thickness is more challenging. This parameter can be estimated, assuming hydrostatic equilibrium (Laxon et al., 2003), from the measurement of the sea ice freeboard, i.e. the height of the ice surface above the local sea level. In principle, satellite altimetry can be used to measure directly the sea ice freeboard (Laxon et al., 2013; Kwok et al., 2009). In the freeboard-to-thickness conversion the freeboard and the associated errors are typically multiplied by a factor of $\sim 9.6$ (Wingham et al., 2006), thus, it is fundamental to both improve the accuracy of freeboard estimates as well as to minimise their uncertainty.

Armitage and Davidson (2014) have demonstrated that CryoSat-2's interferometric mode (SARIn) enables to process waveforms whose power echo is dominated by the strong reflection from off-nadir leads, as the available phase information can be used to correct for the associated range error. They found that such an error, if left unaccounted for, would cause a significant underestimation of the sea surface height which would, in turn, lead to an overestimation of freeboard heights. This study builds on their work to in- 
vestigate how the decreased uncertainty of the sea surface height, obtained by including more waveforms in the analysis, affects the uncertainty of Arctic sea ice freeboard. Furthermore, airborne laser and radar altimetry as well as snow radar measurements are used to assess CryoSat-2 SARIn performance with regards to Arctic sea ice freeboard estimation.

The next section describes the datasets used in the study, while section 3 provides the necessary theoretical background and the methodology used to process the data acquired by the different sensors. The estimated freeboard heights are presented and discussed in section 4 together with snow depth estimates from several sources. Finally, section 5 summarises the main findings of the study.

\section{Data}

\subsection{CryoSat-2}

A large part of this study deals with the processing of radar altimetry data from the SAR Interferometric Radar Altimeter (SIRAL) on board of CryoSat-2 (CS2). Most of the time SIRAL operates in SAR mode over Arctic sea ice. However, a small region between $80^{\circ}-85^{\circ} \mathrm{N}$ and $100^{\circ}-140^{\circ} \mathrm{W}$ (figure 1) was selected to test the SARIn capabilities over sea ice (Armitage and Davidson, 2014). This area, known as the Wingham box, has been active since CS2 launch in 2010 until October 2014. Post October 2014, SIRAL has acquired data in SAR mode also in the Wingham box.

SARIn data acquired on the 5th of April 2012 along orbit \#10565, inside the Wingham box, have been processed in this study (figure 1). In SARIn mode the CS2 footprint extends for $\sim 1.65 \mathrm{~km}$ in the across-track direction and for $\sim 305 \mathrm{~m}$ in the along-track direction (ESA and UCL, 2014).

This study uses $20 \mathrm{~Hz}$ SARIn waveforms (level 1b product) processed with the baseline $\mathrm{C}$ processor, downloaded from ESA CryoSat ftp client (ftp: //science-pds.cryosat.esa.int).

\subsection{Cryo VEx 2012}

Validation of CS2 freeboard estimates is performed using data collected during the CryoSat Validation Experiment (CryoVEx) 2012, a campaign which took place between the 25th of March and the 5th of May 2012. During the campaign, two aircraft were used to fly several sensors in order to collect data over sea- and land ice along selected CS2 ground tracks (Skourup 


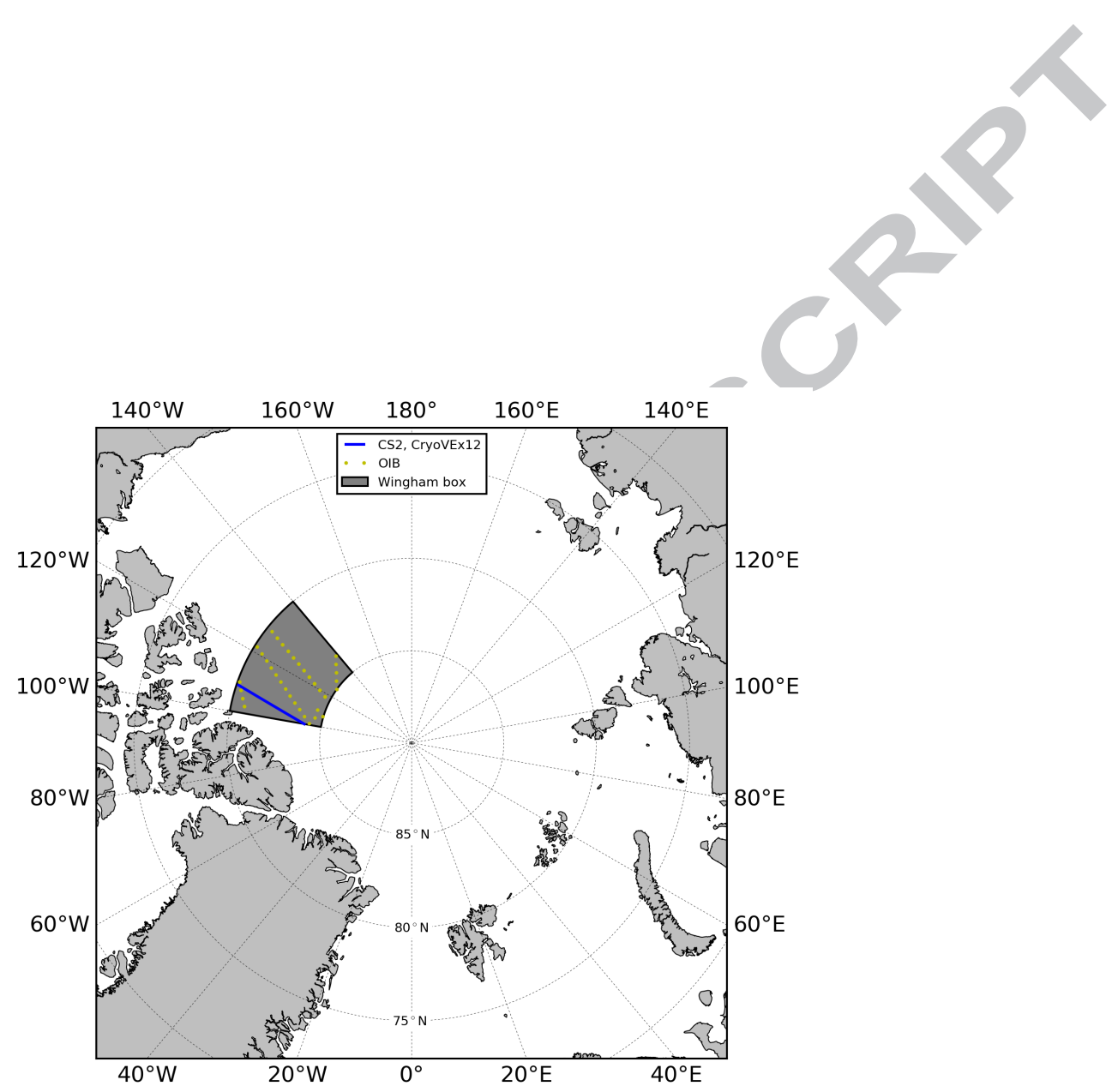

Figure 1: Map of the Arctic Ocean. Wingham box (grey patch), where CryoSat-2 (CS2) was switched to SARIn mode (2010-2014), and tracks where the data have been acquired (blue line for CS2 and CryoVEx and yellow dots for Operation IceBridge (OIB)) 
et al., 2012). One of the aircraft carried an airborne laser scanner ( $A L S)$ and the Airborne SAR Interferometric Radar System (ASIRAS) which provided the data used in this study. Such data were also acquired on the 5 th of April 2012 along the CS2 orbit \#10565, inside the Wingham box (figure 1). The average time difference between the satellite pass $(\sim 14: 00 \mathrm{~h})$ and the aircraft pass $(\sim 18: 30 \mathrm{~h})$ is approximately 4.5 hours.

The ALS is a conventional airborne laser scanner of type RIEGL LMS-Q240i60 operating at a wavelength of $904 \mathrm{~nm}$. Typical resolution of the raw data is approximately $1 \times 1 \mathrm{~m}$ in a $300 \mathrm{~m}$ wide swath at the nominal flight altitude of $300 \mathrm{~m}$. The vertical accuracy is in the order of $10 \mathrm{~cm}$ depending primarily on uncertainties in the kinematic GPS solutions. ALS data were processed at DTU Space to obtain a level 1 product containing the geo-located elevations above the WGS-84 reference ellipsoid together with the relative timestamps.

The ASIRAS radar is an airborne version of the SIRAL radar altimeter onboard CS2. It operates at $13.5 \mathrm{GHz}$ with footprint size $10 \mathrm{~m}$ across track and $3 \mathrm{~m}$ along track in Low Altitude Mode with low resolution (LAMa) at a standard flight height of $300 \mathrm{~m}$. The ASIRAS data used in this study were processed at the Alfred Wegener Institute (AWI) as part of the ESA CryoVal-SI project where they used a Threshold First Maximum Retracker Algorithm (TFMRA) with a $40 \%$ power threshold (Hendricks, personal communication) to obtain a level 2 product containing the geo-located freeboard heights.

\subsection{Operation IceBridge}

In order to account for the snow layer covering the sea ice, snow depth estimates from the IceBridge L4 Sea Ice Freeboard, Snow Depth, and Thickness, Version 1 product (Kurtz et al., 2015) are included in the analysis. The data used in this study $(O I B)$ were acquired during several flights performed between the 14th and the 29th of March 2012 (figure 1). At the $460 \mathrm{~m} \mathrm{nom-}$ inal flight altitude the snow radar has a footprint size of $11 \mathrm{~m}$ across track and $14.5 \mathrm{~m}$ along track. The product, containing snow depths averaged every 40 $\mathrm{m}$ in the along-track direction (Kurtz et al., 2015), can be downloaded from the NASA NSIDC website (https://nsidc.org/icebridge/portal/). 


\subsection{Envisat}

With regards to the capacity of CS2 to detect off-nadir leads, additional validation is performed using spatially and almost temporally coincident $\mathrm{SAR}$ imagery from the Advanced Synthetic Aperture Radar (ASAR) instrument on board of Envisat, acquired just three days before losing contact with the satellite. The Wide Swath Mode level 1b product (version 6.02) used in this work is available at the ESA Earth Online portal (https://earth.esa. int/).

\section{Methods}

The main objectives of this study are 1) to make an assessment of Arctic sea ice freeboards derived from SIRAL measurements and 2) to investigate the possible reduction in the freeboard uncertainty achievable using SIRAL interferometric capabilities.

The first objective is accomplished by comparing SIRAL freeboard heights with those from ALS and ASIRAS as illustrated in figure 2. Snow depth estimates from the Warren climatology and the OIB snow radar are used as an additional input in section 4 to discuss the results obtained in the study. A detailed description of the processing steps applied to SIRAL, ALS and ASIRAS/OIB datasets is included in sections 3.2, 3.3 and 3.4, respectively. The possible reduction in the SIRAL freeboard uncertainty, introduced in section 3.1.1, is investigated by comparing two scenarios: a SAR-like scenario, where ambiguous waveforms are discarded and the phase information not used, and a scenario in which some of the ambiguous waveforms are processed together with their phase information (section 3.2).

\subsection{Freeboard estimation}

The definition of freeboard depends on the wavelength of the altimetry sensor used to observe sea ice and, thus, it differs for radar and laser altimetry. In general, one can say that the freeboard is determined by subtracting the local sea surface height from the height of the sensed surface as:

$$
F=h-S S H
$$

where $h$ is the height of the sensed surface, snow for the ALS instrument and somewhere between snow and sea ice for SIRAL and ASIRAS, and $S S H$ is the actual sea surface height. The actual SSH in regions covered by sea ice is 


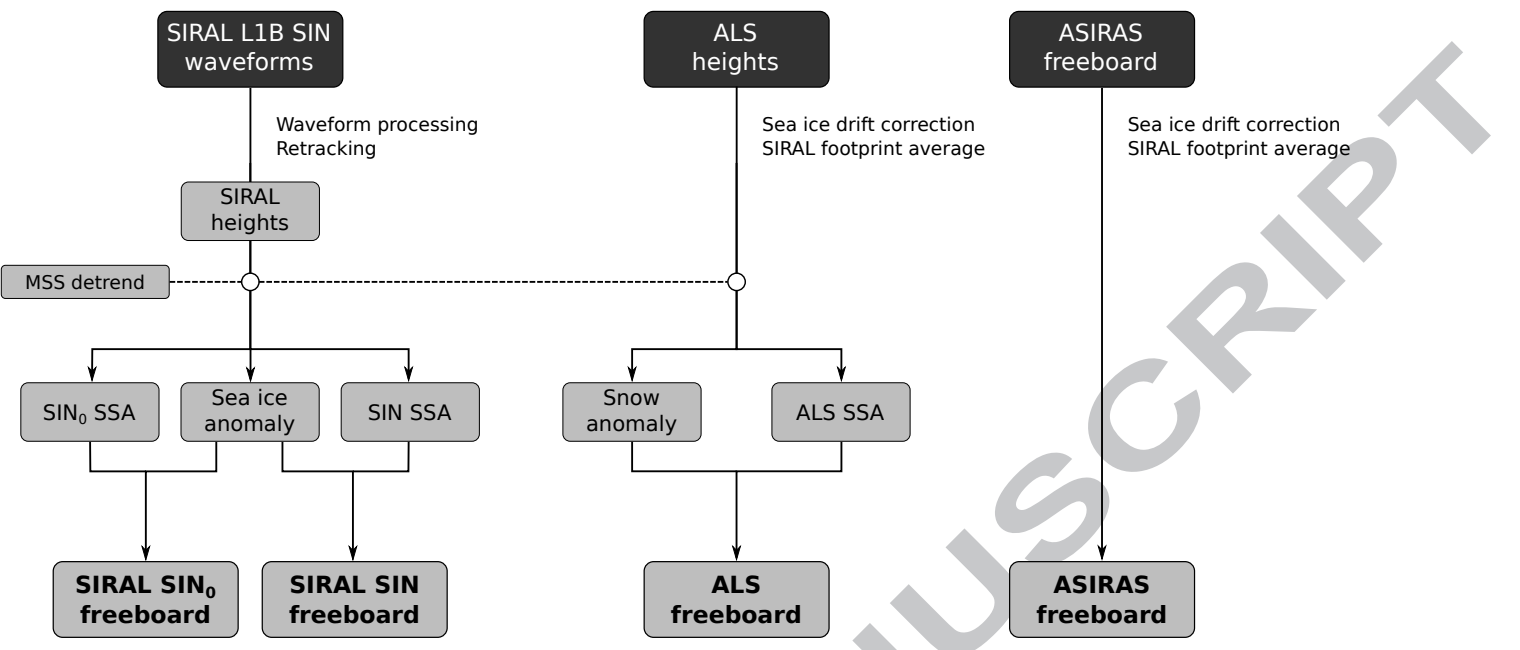

Figure 2: Simplified block diagram illustrating the methods used to estimate freeboard from different sensors. The dark grey blocks on the top represent the datasets used in this study, described in detail in section 2. The estimated freeboards, blocks with bold text at the bottom of the figure, are presented and discussed in section 4. Everything else in between the top and the bottom blocks describes the processing steps applied to the respective datasets, which is the subject of section 3

determined by interpolating between lead height estimates. The elevations are first detrended using a mean sea surface $(M S S)$ to improve the accuracy of the interpolated SSH. In fact, subtracting the MSS from the elevations removes the major component of the height measurement due to the geoid (Skourup et al., 2017) as well as it accounts for higher frequency variations in the SSH. Since $S S H=M S S+S S A$, the freeboard can be determined as

$$
F=h-M S S-S S A
$$

where $S S A$ is the sea surface anomaly (figure 3 ). In this study all elevations are detrended using the DTU15 MSS (Andersen et al., 2016).

As a layer of snow on the sea ice would reduce the radar propagation speed (Kurtz et al., 2014), a correction based on assumed snow depth, penetration and density should be applied to radar sea ice elevations (section 3.2).

\subsubsection{Freeboard uncertainty}

The total uncertainty on a generic measurement is the result of the contributions from systematic and random uncertainties. While systematic errors can usually be corrected for, random errors can be minimised by increasing 


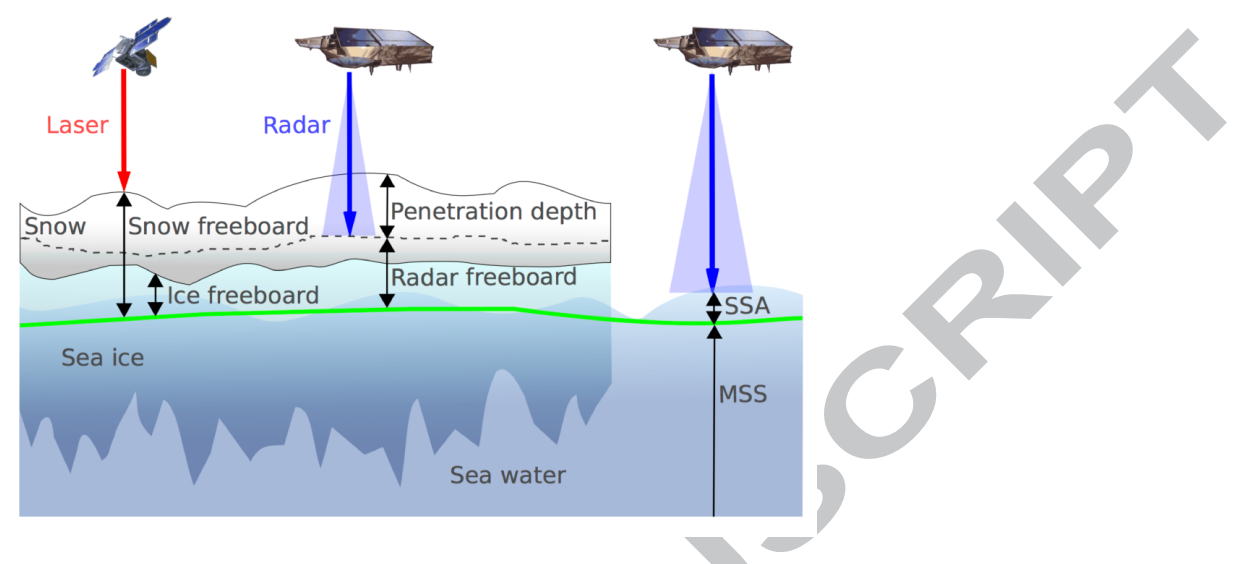

Figure 3: Instrument-dependent freeboard. While laser altimeters like ALS sense the snow surface, the CryoSat-2 Ku-band radar altimeter (SIRAL) penetrates the snowpack, with a penetration depth dependent on snow properties. The drawing also shows that the actual sea surface height equals the sum of the mean sea surface (MSS) and the sea surface anomaly (SSA). Credits: (Ricker et al., 2014)

the number of measurements. This study focuses on the random part of the radar freeboard uncertainty since it is the quantity that could possibly be reduced by including more data into the analysis.

Wingham et al. (2006) discusses different types of error from CS2 measurements over sea ice. Random errors originate from random fluctuations during measurements and are assumed to be governed by instrument system errors, affecting the range measurements, as well as by the uncertainty on the actual sea surface height, affecting directly freeboard retrievals (Ricker et al., 2014). Concerning the SIRAL instrument system error, this contribution has been analysed in detail in Wingham et al. (2006) and it is found to be dominated by the SIRAL speckle noise for both SAR $(0.10 \mathrm{~m})$ and SARIn $(0.14 \mathrm{~m})$ modes. However, some errors also arise from orbit determination procedures $(0.06 \mathrm{~m})$ - which are again common to both modes - and from the accuracy of angle measurements $(0.015 \mathrm{~m})$ - for SARIn only. When these contributions are combined in a RSS fashion, they quantify the total elevation error associated to a single SIRAL level $1 \mathrm{~b}$ measurement $\left(\sigma_{l 1 b}\right)$ as $0.116 \mathrm{~m}$ for the SAR mode and $0.153 \mathrm{~m}$ for the SARIn mode.

On the other hand, the uncertainty of the actual sea surface height depends on the abundance of detected leads which are needed for an accurate interpolation of the sea surface anomaly (Ricker et al., 2014). The uncertainty of the sea surface anomaly $\left(\sigma_{S S A}\right)$ is indeed determined by taking the stand- 
ard deviation of the lead elevations detected along the track within a $25-\mathrm{km}$ moving window. If no leads are detected inside the window, $\sigma_{S S A}$ takes the value of the deviation of the interpolated SSA from the mean CS2 elevation (Ricker et al., 2014).

The instrument system error and the uncertainty of the actual sea surface height can be combined to obtain the total random uncertainty of an individual radar freeboard measurement by adding up the variances

$$
\sigma_{F_{R}}^{2}=\sigma_{l 1 b}^{2}+\sigma_{S S A}^{2}
$$

This way of combining different sources of error would require them to be uncorrelated. This condition is probably not completely satisfied in this case, for instance, one could state that the speckle noise affects in some way the uncertainty of the SSA. However, due to the way in which $\sigma_{S S A}$ is determined, its value is strongly governed by the number of detected leads and not by the error on the range measurement. Therefore, in this study the single uncertainties of the range measurements and sea surface anomaly are assumed to be uncorrelated, although it is acknowledged that the total radar freeboard uncertainty is an approximation resulting from a lack of knowledge of the covariance of individual error contributions (Ricker et al., 2014).

The random uncertainty of the ALS snow freeboard is estimated following the approach in (Hvidegaard and Forsberg, 2002) as

$$
\sigma_{F_{S}}^{2}=\sigma_{A L S}^{2}+\sigma_{f i l t}^{2}
$$

where $\sigma_{A L S}$ is the vertical accuracy of the ALS instrument, reported in Skourup et al. (2012) to be approximately $0.10 \mathrm{~m}$, and $\sigma_{\text {filt }}$ is the error due to the filtering parameters chosen for the lead detection algorithm explained in section 3.3.3. This value is estimated to be approximately $0.05 \mathrm{~m}$ (Hvidegaard and Forsberg, 2002).

\subsection{SIRAL data processing}

This section describes the methods used to estimate surface elevations from the SIRAL $20 \mathrm{~Hz}$ SARIn waveforms (3.2.1) as well as how the SIRAL $\mathrm{SSA}$ is determined (3.2.2). 


\subsubsection{Elevations}

In the first place, the quality of the waveforms is assessed according to their signal-to-noise ratio $(S N R)$, computed as

$$
S N R=10 \log _{10}\left(\frac{P_{\max }}{P_{N}}\right)
$$

where $P_{\text {max }}$ is the waveform maximum power and $P_{N}$ is the thermal noise of the waveform, defined in Vignudelli et al. (2011) as

$$
P_{N}=\frac{1}{5} \sum_{i=1}^{5} P_{i}
$$

Here, $P_{i}$ is the power at the $i$-th gate of the waveform. Waveforms having $S N R<15 \mathrm{~dB}$ are considered to be too noisy to allow for the identification of a clear leading edge and are therefore discarded. The value of this threshold is chosen using a trial and error approach based on the analysis of a large number of waveforms covering different areas of the Arctic Ocean (Di Bella, 2015).

The pulse peakiness $(P P)$ of the remaining waveforms is computed as (Armitage and Davidson, 2014)

$$
P P=\frac{P_{\max }}{\sum_{i=1}^{N_{g}} P_{i}}
$$

where $N_{g}$ is the total number of gates. Waveforms having $P P<0.012$ are discarded, since they are considered to be generated by reflections coming from the ocean. In this case, the PP threshold is derived from the results in (Ricker et al., 2014).

Waveform classification is then performed taking inspiration from Armitage and Davidson (2014). Leads and sea ice are identified using two PP thresholds, namely a high threshold $\left(P P_{h}\right)$ and a low one $\left(P P_{l}\right)$.

All waveforms having $P P>P P_{h}$ present a purely specular feature which can be associated to a reflection coming from a lead relatively close to the satellite nadir. On the other hand, waveforms with $P P<P P_{l}$ are characterised by a purely diffusive feature which is the result of the radar signal being reflected by a rougher surface like sea ice. The value of $P P_{h}$ and $P P_{l}$ is set 
in this study to 0.25 and 0.045 , respectively (Kildegaard Rose, 2013).

The remaining waveforms having $P P_{l}<P P<P P_{h}$ usually present both specular and diffusive features and they are classified in this study as mixed. In order to assess how the number of processed waveforms affects the total random freeboard uncertainty, two scenarios are defined:

- $S I N_{0}$, a SAR-like scenario where only waveforms with $P P>0.25$ are processed and the phase information is discarded

- $S I N$, where waveforms with $P P>0.09$ (Di Bella, 2015) are processed as they are considered to generate from leads. Additionally, the phase information is used to estimate the exact location of the scattering point on the ground.

Waveforms with $0.045<P P<0.09$ are not processed in this study because of their more ambiguous nature.

In this work sea ice waveforms are retracked with a 50\% Threshold FirstMaximum Retracker Algorithm (TFMRA50) (Ricker et al., 2014). In this way, the first local maximum of the waveform, usually associated with a return from ice floes, is retracked. The noise in front of the leading edge is suppressed by using a dynamic power threshold, defined as a percentage of the maximum power of the waveform. The first local maximum is then individuated as the first peak being larger than such a threshold. The exact retracking gate on the leading edge is finally obtained by linearly interpolating between the gates adjacent to ca. the $50 \%$ of the power of the first peak (for more details, see Ricker et al. (2014)).

The same threshold retracker, adapted to retrack the peak corresponding to the maximum waveform power, instead of the first one, is used to retrack both leads and mixed waveforms.

The lower radar propagation speed through the snowpack is addressed by adding to the SIRAL sea ice elevations the correction (Kwok and Cunningham, 2015)

$$
h_{c}=h_{s}\left(1-\frac{c_{s}\left(\rho_{s}\right)}{c}\right)
$$

where $h_{s}$ is the snow depth and $c_{s}\left(\rho_{s}\right) / c$ is the ratio between the speed of light in snow, dependent on the snow density $\rho_{s}$, and in space. Following Kwok 


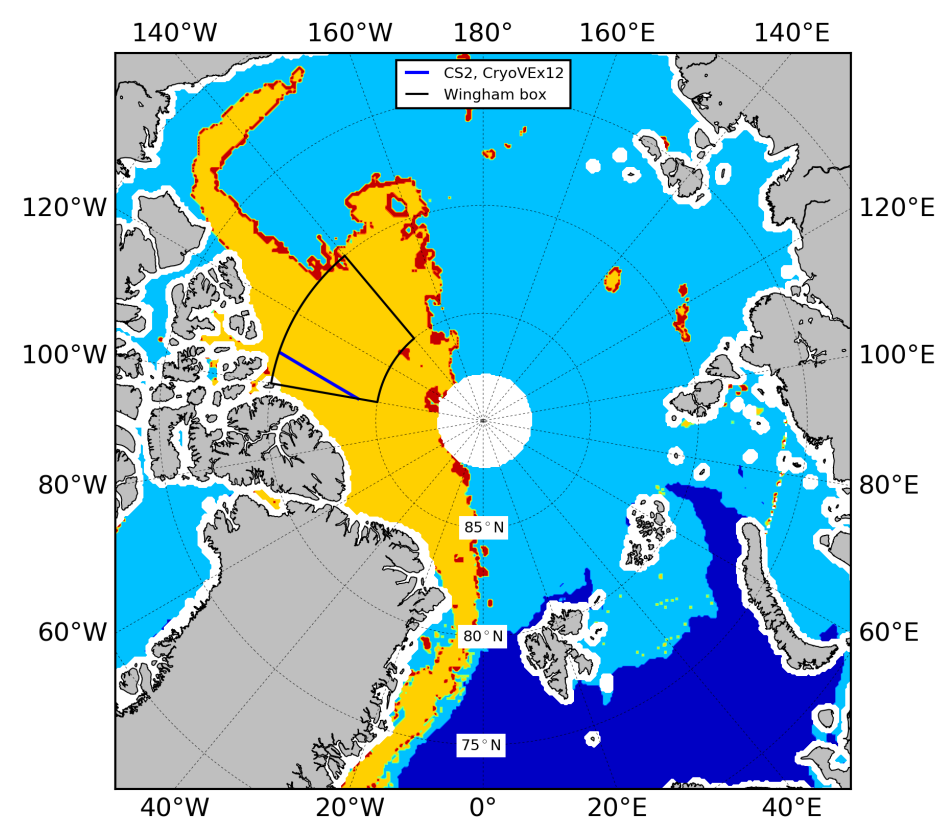

Figure 4: Sea ice type from the OSI-SAF product on $5 / 4 / 2012$, showing areas of open water (dark blue), first-year ice (light blue), multi-year ice (yellow) and ambiguous ice type (red). The dark blue line represents the track where the SIRAL, ASIRAS and ALS data used in this study have been acquired

and Cunningham (2015), the snow depth and density in equation 8 used in this study are the time- and space-varying estimates from the Warren climatology (W99) (Warren et al., 1999). Recent studies suggest that the W99 climatology does not represent very accurately the Arctic snow properties in the last years (Kurtz and Farrell, 2011; Newman et al., 2014), probably due to the decrease of multi-year ice (MYI) in the Arctic Ocean (Maslanik et al., 2011; Comiso, 2012; Polyakov et al., 2012). Modified versions of W99, scaling the snow depth values on first-year ice (FYI), have been suggested to partially overcome this issue (Laxon et al., 2013). However, in this work the classic version of W99 is used, based on the information available from the OSI-SAF sea ice type product on the 5th of April 2012, which shows mainly MYI inside the Wingham box (figure 4).

In the SIN scenario, where waveforms with a lower PP are included into the analysis, the strong reflection of scattering targets lying several kilometres away from nadir can contaminate the signal picked up by the radar 


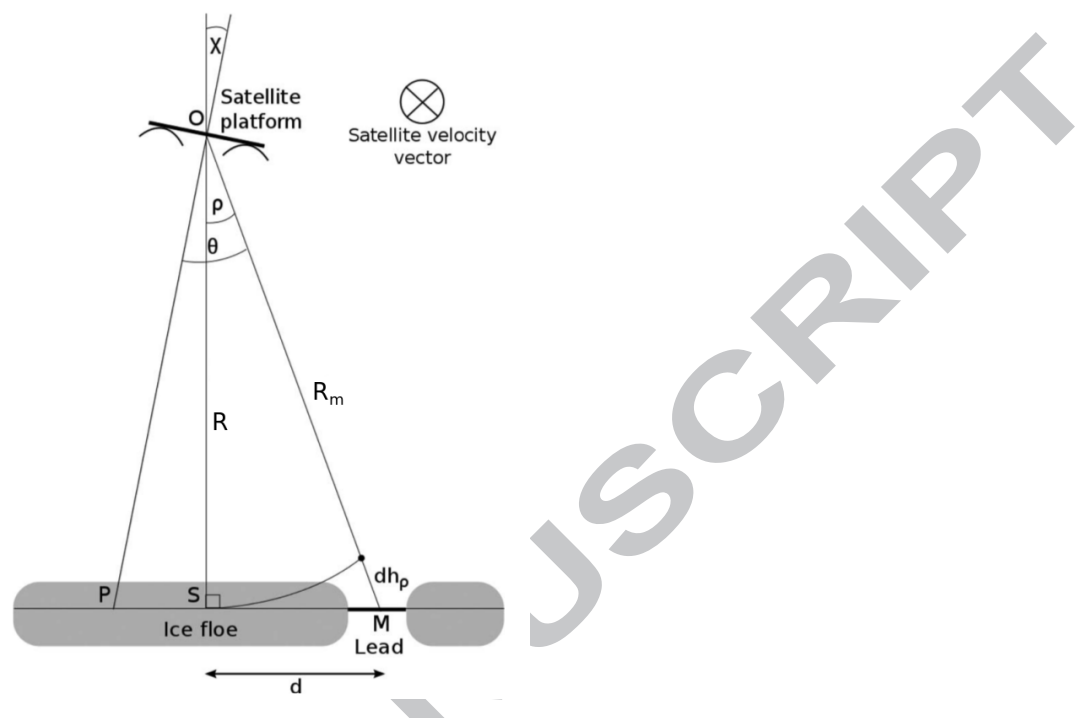

Figure 5: Geometry for the off-nadir range correction (ONC). Off-nadir leads can cause an overestimation of the range, as $R_{m}>R$. The phase information available in the CryoSat-2 SARIn mode enables to compute the ONC ( $d h_{\rho}$ in the figure) and to correct for the range overestimation. In the drawing the satellite velocity vector enters the page. Modified from Armitage and Davidson (2014)

(Armitage and Davidson, 2014; Abulaitijiang et al., 2015). A typical situation over sea ice is shown in figure 5 where the range $R_{m}$ to an off-nadir lead is measured by the radar instead of the correct range $R$ (Armitage and Davidson, 2014). Using the interferometric capabilities of CS2, it is possible to determine the across-track distance $d$ to the scatterer and thus to correct the range measured by the satellite accordingly. In fact, when the scatterer - in this case the lead - is not exactly at nadir, the reflected signal travels different distances to the two SIRAL's antennas and therefore it is detected by them with two different phases. This difference can be used to compute the angle $\theta$, subtended between the antenna boresight direction and the direction of the lead. Together with the roll angle provided by the star tracker on board of CS2, it is possible to compute the angle $\rho$ measured from the local vertical to the direction of the lead (Armitage and Davidson, 2014). The across-track distance to the lead can then be calculated using the small-angle approximation as

$$
d=R_{m} \sin (\rho) \simeq R_{m} \rho
$$

and the consequent off-nadir range correction (ONC) is obtained through the 
relation

$$
d h_{\rho} \simeq \eta R_{m} \frac{\rho^{2}}{2}
$$

where $\eta$ is a geometric factor used to correct for the curvature of the Earth (Wingham et al., 2004; Galin et al., 2013). The corrected range $R$ in case of flat surface assumption is then obtained as

$$
R=R_{m}-d h_{\rho}
$$

The ONC is applied only in the SIN scenario.

\subsubsection{Sea surface anomaly}

The lead elevations obtained through the retracking procedure identify the local SSH. The local SSA is then obtained by subtracting from it the MSS at the lead locations, as

$$
S S A=S S H-M S S
$$

The SSA at the sea ice locations is obtained by along-track linear interpolation and, finally, by applying a running mean filter with $25-\mathrm{km}$ width, to smooth jumps that can occur in dense lead clusters due to the signal noise (Ricker et al., 2014).

\subsection{ALS data processing}

\subsubsection{Sea ice drift}

In the first place, a sea ice drift correction is applied to the ALS measurements to account for the 4.5 hours difference between the satellite and aircraft passes. Drift velocity vectors derived from repeated SAR images are provided by R. Saldo from DTU Space. The drift for each ALS measurement is obtained by using a nearest neighbour approach and is found to be very low in the area. As a consequence, the drift-corrected ALS measurements are shifted slightly to the West, but still within the CryoSat-2 footprint area (Di Bella, 2015).

\subsubsection{Elevations}

In order to compare heights and freeboard values from SIRAL and ALS, it is crucial to average the elevations retrieved by the ALS instrument to the SIRAL footprint. There exist many ways of doing it as discussed in Kildegaard Rose (2013). In this study, ALS measurements are averaged using 
their distance from the satellite nadir as a weight. Along the analysed track, each SIRAL footprint contains on average 30000 ALS point measurements, thus, lead heights will be averaged out during the process.

\subsubsection{Sea surface anomaly}

The determination of the ALS SSA requires a different approach from the one used for SIRAL since no information about the ALS waveforms is available in the data acquired for this study and, thus, leads cannot be identified in the way used for the radar case. In this study, the lead heights are extracted by looking for minima in the elevation profile following an approach similar to the one in Hvidegaard and Forsberg (2002). In the first place, the elevation profile is detrended using the MSS to remove the main features of the sea surface height. The minimum height is then found for 50 s intervals and these minima are averaged in groups of three. The resultant points are considered to represent lead elevations. This process is equivalent to apply a high-pass filter with a filtering parameter of approximately $150 \mathrm{~s}$, which corresponds to about $10 \mathrm{~km}$ on ground considering that the aircraft flies at $250 \mathrm{~km} / \mathrm{h}$ (Hvidegaard and Forsberg, 2002).

The SSA is finally obtained by linear interpolation of the lead elevations to the sea ice locations identified by SIRAL.

\subsection{ASIRAS and OIB data processing}

Level 2 freeboard heights from ASIRAS are corrected for sea ice drift and averaged to the SIRAL footprint as explained in sections 3.3.1 and 3.3.2, respectively. The results are then compared directly to ALS and SIRAL freeboard estimates. No correction accounting for the lower radar propagation speed through the snow is applied to the ASIRAS freeboards as, at the time of writing, it was not clear if it was already applied by the AWI processor. As shown in figure 1, OIB snow depths are not available exactly along the CS2/CryoVEx track. After a further 50-km along-track averaging, snow depth at the desired locations are obtained by linear interpolation of all OIB acquisitions inside the Wingham box. Even though the time of such acquisitions spans from 22 to 7 days prior the CS2 pass, no sea ice drift correction is applied so that the resulting along-track estimates represent solely a rough reference for snow depth in the study area during March 2012. Such a reference is used, together with snow depth estimates from the W99 climatology, to qualitatively assess the penetration of the Ku-band signal from ASIRAS and SIRAL into the snowpack. 


\section{Results and Discussion}

\subsection{CS2 lead detection}

In this work, the phase information provided by the CS2 SARIn acquisition mode is used to determine the across-track distance of leads from nadir and to compute the respective ONC (in the SIN scenario). Two examples showing the capability of SIRAL to detect off-nadir leads can be observed in figure 6 where the red dots represent the location of the waveforms classified as leads and relocated using the computed across-track distance. Dark areas in the Envisat image on the background correspond to a low value of backscatter coefficient which, for a slant-looking instrument like the ASAR, can be associated to specular surfaces, i.e. leads. It can be generally observed that the across-track distance computed using the phase information is quite accurate since practically every red dots lies on top of a black spot of the ASAR image. The furthest off-nadir lead detected by SIRAL is located at $\sim 1500 \mathrm{~m}$ from the satellite nadir (figure 6a) but if, as a test, all mixed waveforms are included into the analysis, it turns out that SIRAL is able to pick up leads up to $\sim 2300 \mathrm{~m}$ from nadir along this specific track (figure $6 \mathrm{~b}$ ). However, as already discussed in section 3.2.1, waveforms with $0.045<P P<0.09$ are mostly ambiguous and difficult to retrack and therefore discarded.

These examples show that the phase information available in the SARIn mode gives CS2 an excellent capacity to determine the across-track distance of the detected leads.

\subsection{Elevations and $S S A s$}

The top plot in figure 7 shows SIRAL lead height anomalies from the MSS, distributed around a mean value of ca. $-1.01 \mathrm{~m}$, with several points lying below $-2 \mathrm{~m}$. Large ONC values, computed for each lead height and shown in the middle plot, correspond to very low height anomalies suggesting the latter to be caused indeed by off-nadir leads. The bottom plot shows the height estimates corrected with the $\mathrm{ONC}$, i.e. the sum of the top and middle plots, having a mean value of ca. $-0.92 \mathrm{~m}$. It is observed that some of the corrected heights are still close to $-2 \mathrm{~m}$ which suggests that, in this case, the $\mathrm{ONC}$ is not able to completely correct every underestimated lead height. A deeper analysis relates these heights with waveforms having a value of PP close to the cutoff threshold of 0.09. This highlights the importance of the thresholds used for waveform classification and suggests that further investigation might be needed in that regards. 


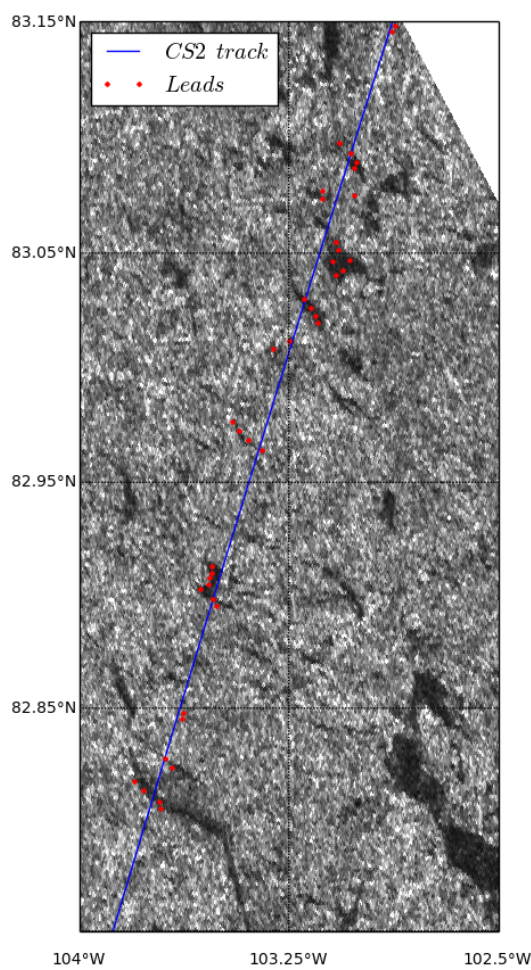

(a)

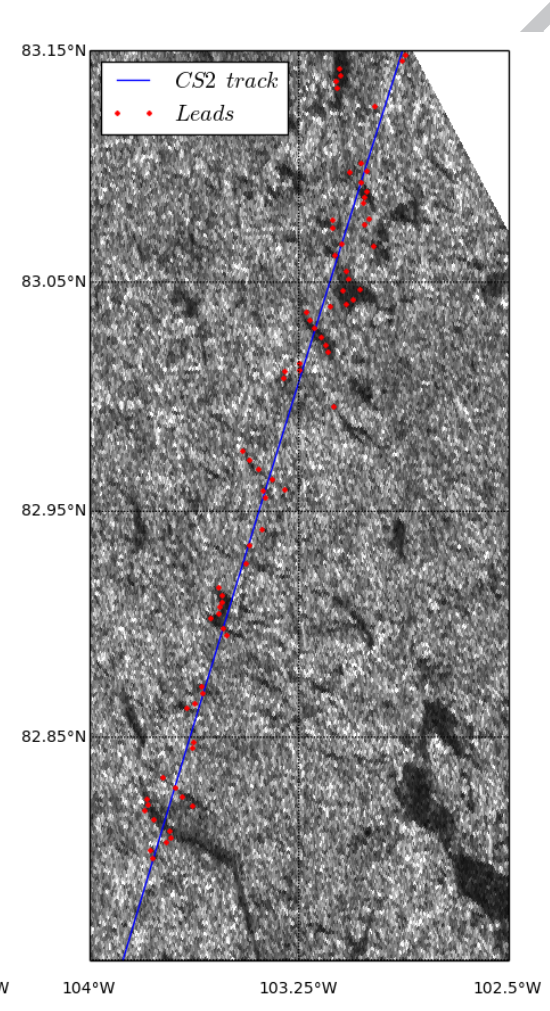

(b)

Figure 6: Segment of CryoSat-2 (CS2) orbit (blue line) on top of an ASAR WSM image from Envisat. The leads detected by SIRAL (red dots) are relocated off-nadir using the SARIn phase information, showing an excellent match with the leads detected by the ASAR instrument (black pixels). In (a) all waveforms with pulse peakiness larger than 0.09 are processed as leads while in (b) the threshold is lowered to 0.045 in order to assess SIRAL lead detection capabilities 

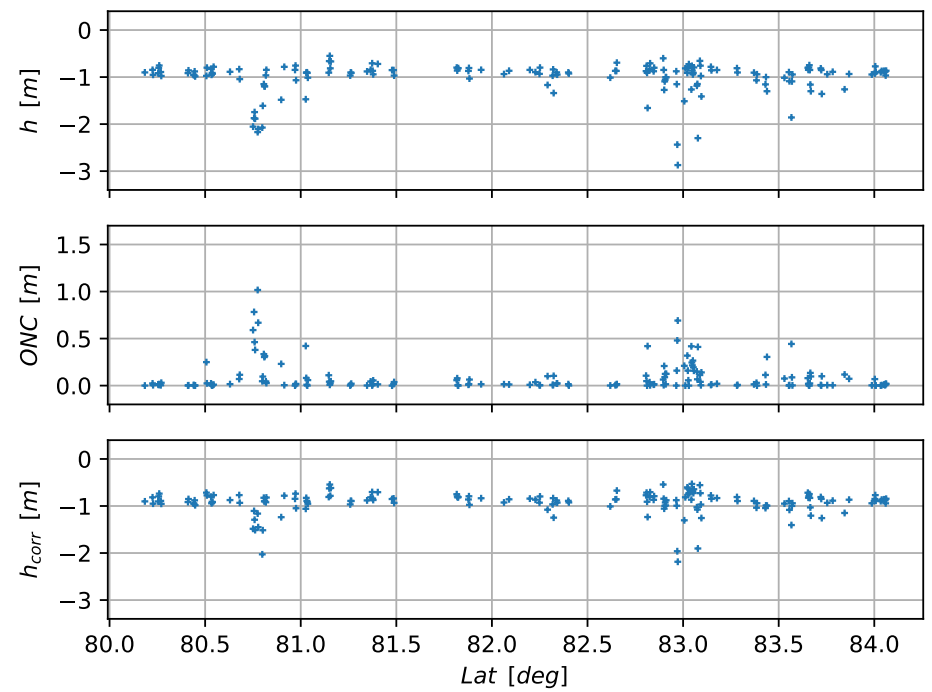

Figure 7: SIRAL lead elevations (top), off-nadir correction (ONC) computed using the SARIn phase information (middle) and lead elevations after correction (bottom). All heights are relative to the MSS

Figure 8 shows in blue the height anomalies from the MSS and in red the SSAs obtained processing ALS (8a) and SIRAL data (8b and 8c). As expected, average elevations from ALS $(-0.38 \mathrm{~m})$ are found to be larger than those from SIRAL $(-0.58 \mathrm{~m})$, as they generate from the air-snow interface while SIRAL Ku-band signal penetrates, at least partly, the snowpack. In the results from SIRAL it can be noticed that some of the retracked radar elevations lie below the corresponding SSA, which is mainly attributed to instrument noise on the measurements and to the uncertainty of the estimated SSAs.

The SSAs in figure 8 look quite different from each other. In particular, the SIN $_{0}$ SSA looks smoother than the others as only 15 leads are detected along the satellite track, compared to the 170 and 43 lead heights used in the SIN scenario and for the ALS SSA, respectively. The large variation in the SIN SSA observed around $83^{\circ}$ (figure 8c) is caused by the underestimated lead heights visible in figure 7 , thus, it is likely not to reflect a real variation of the SSA.

The ONC can correct for most of the underestimated lead heights which are then used to estimate the SSA. The SSA has a great impact on freeboard estimates as discussed further in section 4.3. 


\begin{tabular}{lccc}
\hline Scenario & $\mu_{\mathbf{F}} \pm \sigma_{\mathbf{F}}^{\mathbf{2}}[\mathbf{m}]$ & $\Delta \mu_{\mathbf{F}}[\mathbf{m}]$ & $\sigma_{\text {red }}^{\mathbf{2}}[\%]$ \\
\hline ALS & $0.83 \pm 0.01$ & - & - \\
ASIRAS & $0.39 \pm 0.10$ & 0.44 & - \\
SIN $_{\mathbf{0}}$ & $0.32 \pm 0.10$ & 0.51 & - \\
SIN & $0.32 \pm 0.06$ & 0.51 & 40 \\
\hline
\end{tabular}

Table 1: Mean values $\left(\mu_{F}\right)$ and associated uncertainties $\left(\sigma_{F}^{2}\right)$ of the ALS, ASIRAS and SIRAL freeboards. $\Delta \mu_{F}$ are the deviations from the ALS snow freeboard and $\sigma_{\text {red }}^{2}$ represents the reduction of the uncertainty observed for the SIN scenario compared to the uncertainty of the $\mathrm{SIN}_{0}$ scenario

\subsection{Freeboard and uncertainty}

In figures 9a to 9d the ALS snow freeboard and the ASIRAS radar freeboard are compared directly with the SIRAL radar freeboard estimated for the different scenarios (mean values in table 1 ).

No spatial correlation is observed between satellite and airborne freeboards in any of the cases along the chosen track. The lack of correlation could depend on several factors. The first, and probably the most important, is the difference in the instruments' footprint size. Although ALS and ASIRAS data have been averaged along-track to the SIRAL footprint, the measurements cover only approximately $300 \mathrm{~m}$ and $10 \mathrm{~m}$ across-track, respectively, compared to the $1600 \mathrm{~m}$ covered by SIRAL. Thus, the instruments might be looking at different surfaces. While this would not affect significantly the average freeboard, it might affect spatial correlation at the footprint scale. Such a low correlation is also found as a result in the ESA CryoVal-SI project (Haas et al., 2016) where the authors show how additional along-track averaging on increasingly larger distances improves significantly the spatial correlation between SIRAL and airborne freeboards. The footprint issue is also supported by figure $9 \mathrm{e}$ which shows a good correlation (0.69) between ALS and ASIRAS freboards.

Other factors impacting the spatial correlation are the algorithms used to estimate the SSA, as the SSA spatial variations reflect directly on the freeboard estimates, as well as the noise on measurements, as the number of representative measurements in a SIRAL footprint are: 1, 100 and 30000 for SIRAL, ASIRAS and ALS, respectively. 


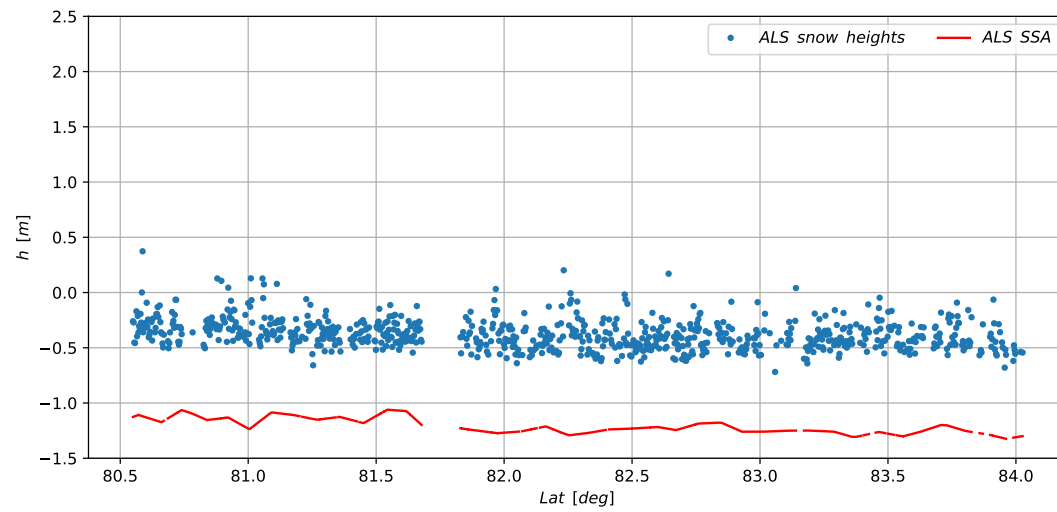

(a)

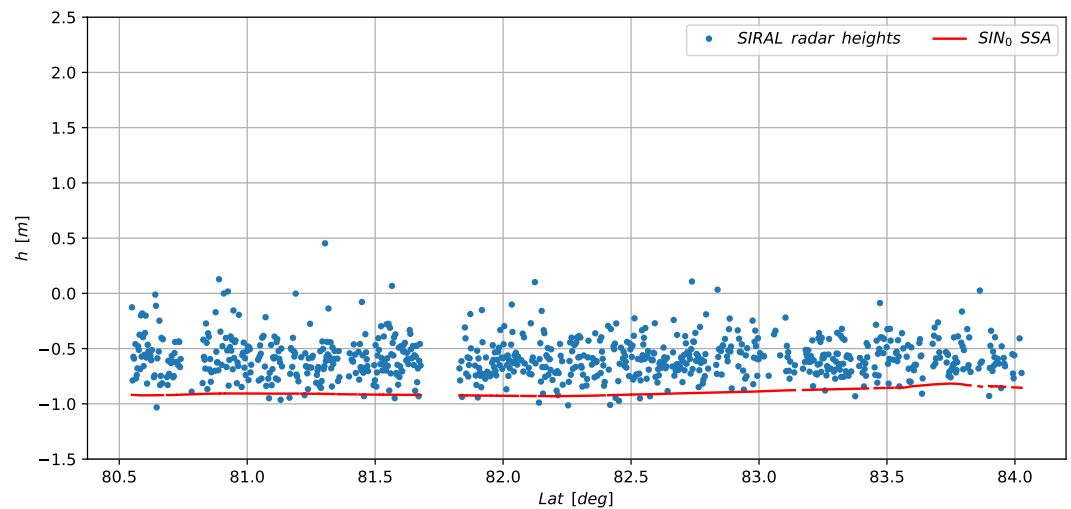

(b)

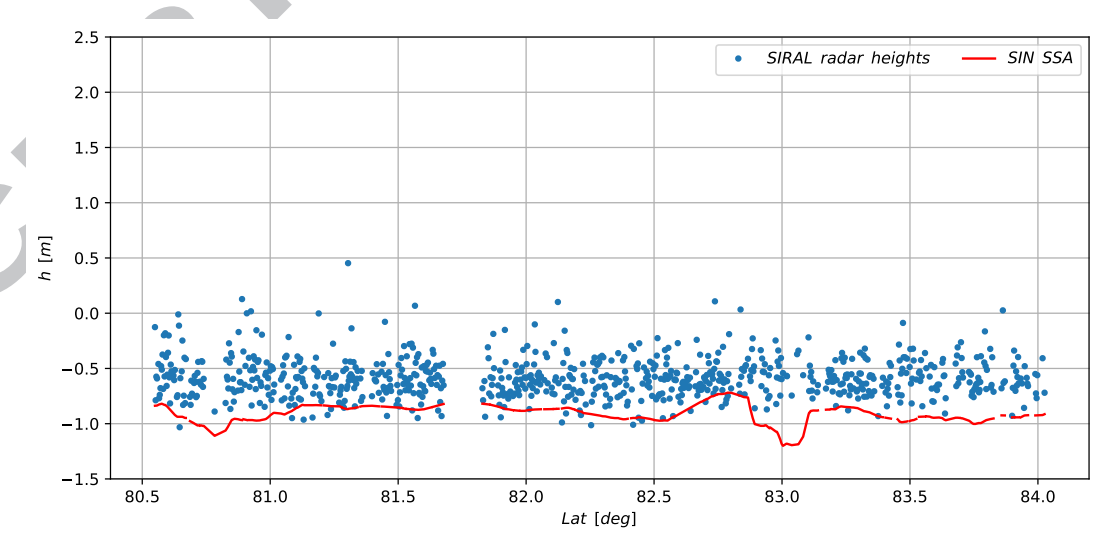

(c)

Figure 8: Elevation profiles from ALS (a) and SIRAL for the $\operatorname{SIN}_{0}$ (b) and SIN (c) scenarios, showed only at locations where valid coincident measurements from all instruments are available. The blue dots represent snow (ALS) and radar (SIRAL) heights above the MSS, while the red lines show the respective6SSAs 


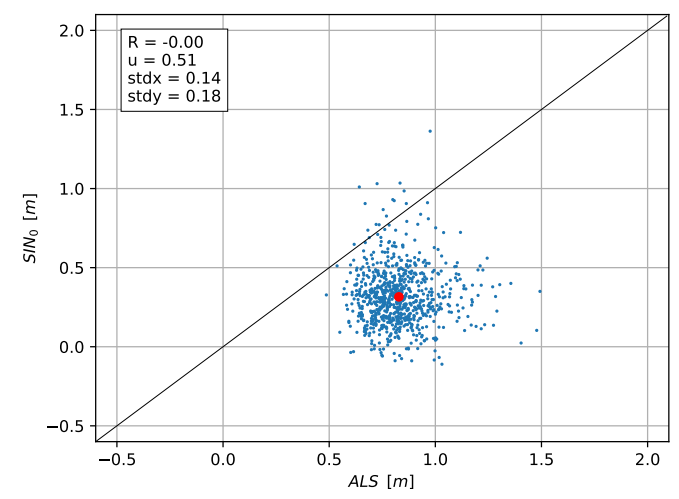

(a)

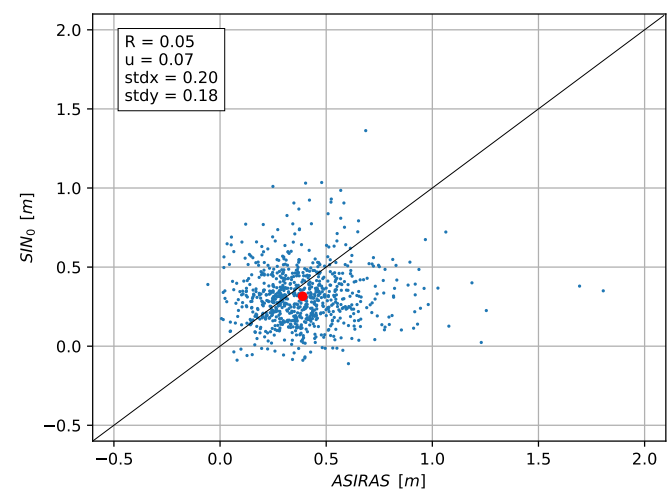

(c)

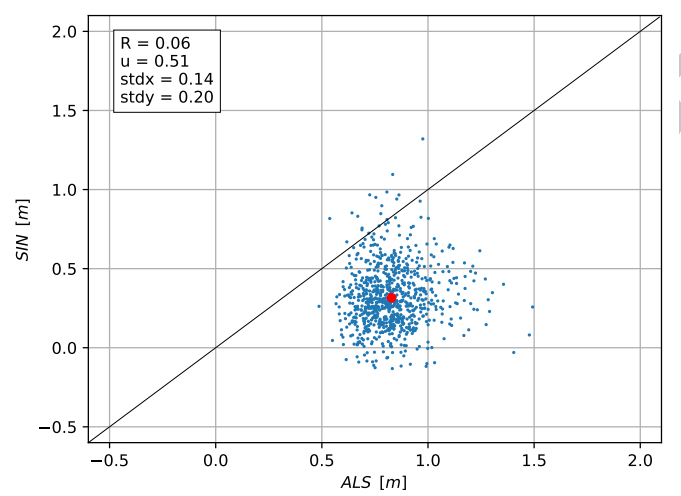

(b)

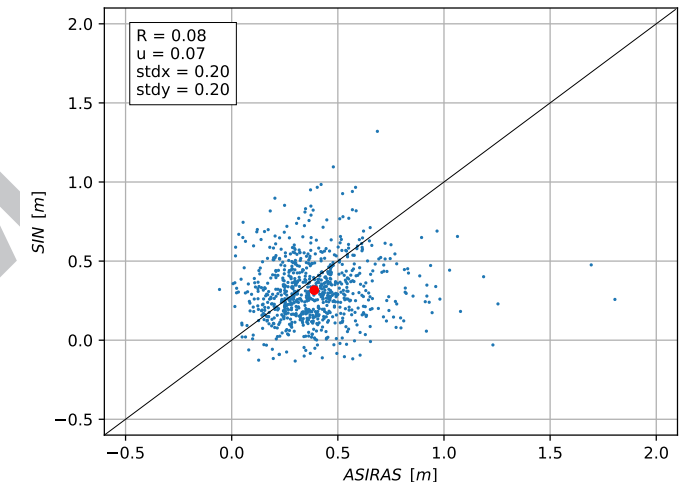

(d)

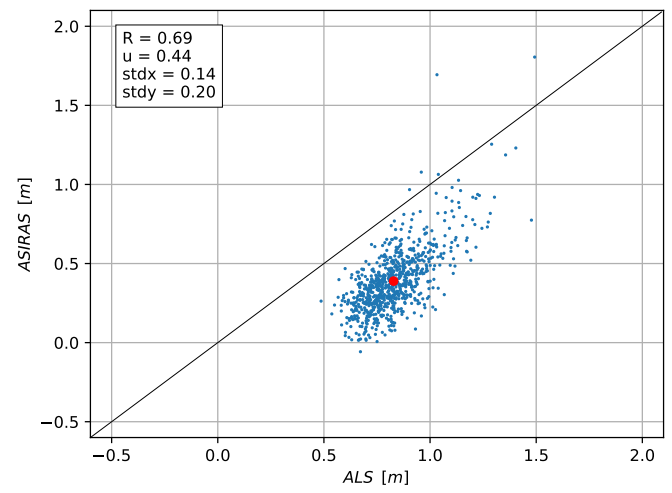

(e)

Figure 9: Correlation plots for all satellite vs. airborne freeboards ((a) to (d)) and for ASIRAS vs. ALS (e). The top-left box in each plot shows values of correlation (R), mean difference $(\mathrm{u})$ and standard deviation for the $\mathrm{x}(\mathrm{stdx})$ and $\mathrm{y}($ stdy) axes 
With regards to the mean values, the snow freeboard tends to be larger than the radar freeboard for all cases, as expected. With a difference of $7 \mathrm{~cm}$, ASIRAS and SIRAL freeboards are in good agreement, taking into account their respective uncertainties in table 1 . The agreement gets better if one considers that ASIRAS data have been retracked at AWI using a TFMRA with a $40 \%$ threshold. Lower thresholds lead, in fact, to higher values of freeboard as reported by Ricker et al. (2014), who estimated the average Arctic freeboard to be $6 \mathrm{~cm}$ larger when using a $40 \%$ threshold, instead of $50 \%$, in March 2013 on MYI. The SIN $_{0}$ and the SIN mean freeboard is found to be the same which suggests that processing ambiguous waveforms with their phase information would potentially not introduce a static bias on the absolute freeboard estimates, although further investigation in this direction is surely required.

The freeboard distribution for all cases can be observed in figure 10. Here, the ALS mode is shifted to the right compared to SIRAL and ASIRAS modes, as expected, since ALS senses the air-snow interface. Furthermore, the ASIRAS, SIN and SIN $_{0}$ modes lie all close to each other, supporting the fact that ASIRAS and SIRAL may have similar scattering horizons. The deviation of the radar freeboards from the snow freeboard might provide information about the average snow depth along the analysed track, topic further discussed in section 4.4 .

Figure 11 shows the along-track snow and radar freeboards for all instruments and scenarios. While the shaded dots identify the freeboard estimated at the single SIRAL measurement locations, the thick solid lines are the result of a 10-km running mean applied to reduce noise and small-scale artefacts (Ricker et al., 2014). It can be observed that the snow freeboard lies on top of the radar freeboard along the entire track. In general, the radar freeboard does not have to follow exactly the same features presented by the snow freeboard since the scattering horizon for the SIRAL and ASIRAS instruments can have along-track profiles different from the air-snow interface. Nevertheless, this is observed quite clearly when comparing ALS and ASIRAS freeboards, while the SIRAL freeboard shows similar features only between approximately $80.5^{\circ}$ and $81.25^{\circ}$ and around $83.5^{\circ}$. An unexpected feature of the SIN freeboard is observed at latitudes between $82.6^{\circ}$ and $83^{\circ}$ and it is caused by the variation observed in the SIN SSA at the same latitudes (figure 8c) already discussed in section 4.2 . 
The most interesting result of this study is perhaps the $\sim 40 \%$ reduction in the total random freeboard uncertainty $\left(\sigma_{\text {red }}^{2}\right.$ in table 1$)$, intended as the reduction of the uncertainty for the SIN scenario when compared to the $\mathrm{SIN}_{0}$ case. Such a value could be further increased by processing larger datasets. However, it has to be noticed that the $\mathrm{SIN}_{0}$ scenario emulates a SAR acquisition, but a real SAR acquisition would be less noisy than a SARIn one due to the higher burst repetition frequency (Wingham et al., 2006). While this is taken into account in the contribution to the freeboard uncertainty $\left(\sigma_{l 1 b}\right)$, the standard deviation of the lead heights would be also slightly reduced in a real SAR acquisition. Nevertheless, the contribution due to the SSA $\left(\sigma_{S S A}^{2}\right)$ is the quantity dominating the total freeboard uncertainty, which value is in turn governed by the number of leads detected along the track. For this reason, it is likely that there would always be a reduction in the total random freeboard uncertainty when including more leads and using the phase information available in the SIRAL SARIn acquisition mode.

Despite the lack of spatial correlation observed between satellite and airborne freeboards, due mainly to the different footprint size, a good agreement is found between average estimates when taking into account uncertainties and the presence of snow (further discussed in section 4.4). Additionally, a significant reduction in the SIRAL random freeboard uncertainty is observed in the SIN scenario, due to the larger number of leads detected along the track.

\subsection{Snow depth}

In this section OIB snow depths are compared with snow depth estimates obtained by subtracting the ALS and the ASIRAS freeboard heights. Monthly values of snow depth from W99 are included as an additional reference.

Figure 12 shows a comparison between the three snow depth estimates, namely W99, OIB and ALS-ASIRAS freeboard heights. The mean values are $0.36 \pm 0.09 \mathrm{~m}, 0.31 \pm 0.06 \mathrm{~m}$ and $0.44 \pm 0.14 \mathrm{~m}$, respectively. The different spatial variability is expected since ALS and ASIRAS measurements are averaged to the SIRAL footprint ( $\sim 300 \mathrm{~m}$ along track), while OIB values are averaged $50 \mathrm{~km}$ along track and W99 values decrease following a second-degree polynomial outside the central Arctic Ocean (Warren et al., 1999). A good agreement is found for all estimates at latitudes between $80.5^{\circ}$ and $81.6^{\circ}$, where the mean snow depth estimates from W99, OIB and ALS-ASIRAS equal $0.35 \mathrm{~m}, 0.32 \mathrm{~m}$, and $0.35 \mathrm{~m}$, respectively. On the other hand, from $81.8^{\circ}$ to $84^{\circ}$ ALS-ASIRAS snow depth seems to deviate from the other es- 


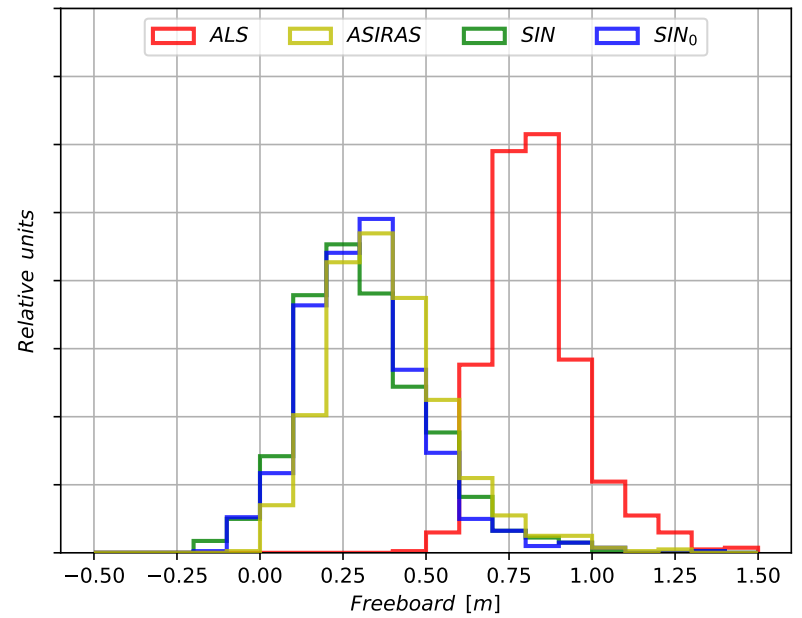

Figure 10: Freeboard distribution corresponding to figure 11. The ALS mode, shifted to the right, and the good agreement between the radar modes support the idea that ASIRAS and SIRAL penetrate the snowpack and might have similar scattering horizons

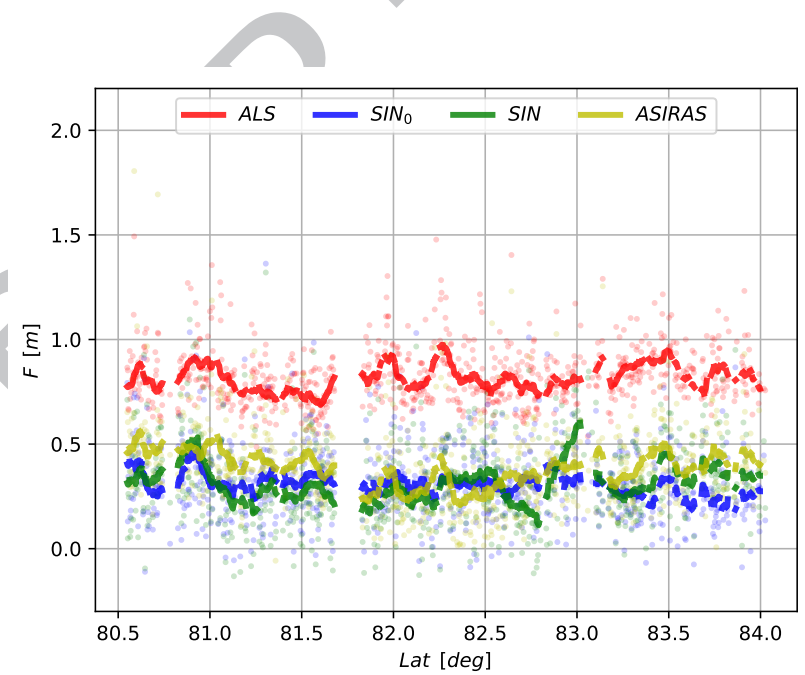

Figure 11: Along-track snow and radar freeboards, showed only at locations where valid coincident ALS, ASIRAS and SIRAL measurements are available. The shaded dots represent estimates at the SIRAL footprint scale while the thick solid lines are the result of a $10-\mathrm{km}$ running mean 
timates up to $\sim 0.25 \mathrm{~m}$. This is the result of the simultaneous decrease in the ASIRAS freeboard and the slight increase in the ALS freeboard observed at the same range of latitudes (figure 11). These variations might be attributed to the way in which the ASIRAS data are processed, however, this is hard to assess as details about the ASIRAS processing were not available at the time this work was carried out. On the other hand, it should be remembered that estimates from the W99 climatology and OIB are only used as a reference in this study and that part of the deviation might be explained by actual snow accumulation.

The average snow depth estimates from W99, OIB and ALS-ASIRAS are additionally compared to the deviations of the average SIRAL radar freeboard from the average ALS freeboard $\left(\Delta \mu_{F}\right.$ in table 1$)$. From table 1 one can see that $\mathrm{ALS}_{-} \mathrm{SIN}_{0}=\mathrm{ALS}-\mathrm{SIN} \approx 0.51 \mathrm{~m}$. This value does not agree in general with the snow depths from W99 and OIB, but it does agree with the ALSASIRAS estimate, taking into consideration the $0.10 \mathrm{~m}$ ASIRAS freeboard uncertainty. This supports the fact that collocated laser and Ku-band radar altimetry measurements could be a valuable combination to estimate snow depth during the spring, when the snow is usually cold and dry. However, during late summers, characterised by wet and warmer snow cover, Ku-band signals would probably not penetrate very much the snowpack. In this regard, it will be interesting to look at the results of the CryoVEx campaign which took place during the fall of 2016.

In general, without collocated accurate snow depth measurements it is not easy to assess snow depth variation, a reason why the authors strongly support the presence of in-situ measurements in the coming CryoVEx field campaigns.

\section{Conclusions}

In this study, measurements from the ALS and ASIRAS instruments collected during the CryoVEx 2012 campaign are used to assess the performance of CS2 along a sea ice-covered track. This is accomplished through the comparison of the heights, SSAs and freeboards estimated using measurements from the three instruments as well as by considering snow depth estimates from the W99 climatology and the OIB campaign carried out in the spring of 2012. Additionally, the phase information provided by the SIRAL SARIn acquisition mode, already used by Armitage and Davidson (2014) to reduce the uncertainty of the sea surface height in ice-covered areas, is used to invest- 


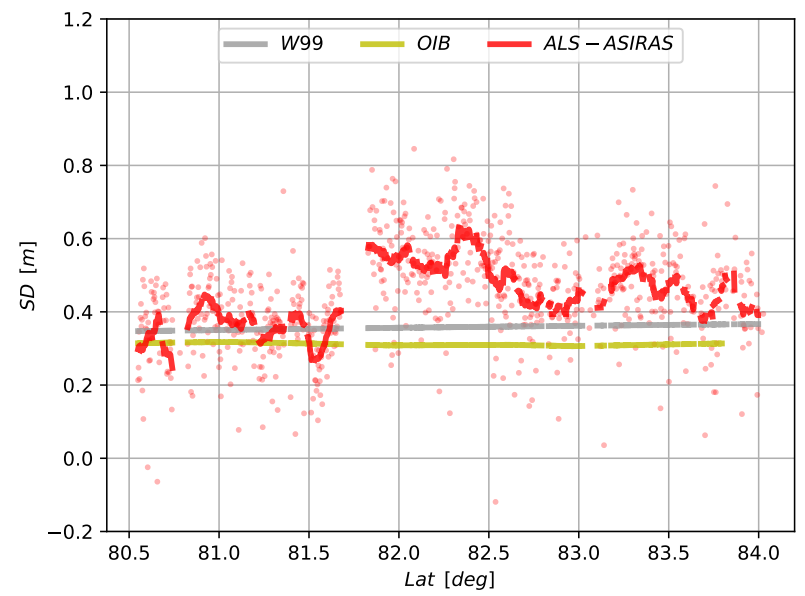

Figure 12: Along-track snow depth estimates from the Warren climatology (W99), Operation IceBridge (OIB) and the ALS snow freeboard minus the ASIRAS radar freeboard. The thick solid red line is the result of a 10-km running mean applied to the shaded red dots

igate the possible reduction in the Arctic radar freeboard uncertainty. This is achieved by defining two scenarios: $\mathrm{SIN}_{0}$, emulating a SAR-like acquisition, and SIN, where the phase information is used to correct the retrieved lead elevations. In the latter scenario, leads are detected up to a distance of $\sim 2300 \mathrm{~m}$ from the satellite nadir.

No spatial correlation is observed between SIRAL freeboards and both ALS and ASIRAS freeboards, which is mainly attributed to the different instrument ground footprint size as well as to the difference in the estimated SSAs. SSA determination is found to be a key aspect when estimating sea ice freeboard.

On the other hand, a very good agreement is observed between the mean ASIRAS $(0.39 \pm 0.10 \mathrm{~m})$ and SIRAL radar freeboards $(0.32 \pm 0.10 \mathrm{~m}$ for the $\mathrm{SIN}_{0}$ and $0.32 \pm 0.06 \mathrm{~m}$ for the SIN scenarios), taking into account the respective uncertainties and the different threshold used during retracking ( $40 \%$ for ASIRAS and $50 \%$ for SIRAL). It is also observed that some features present in the snow freeboard profile from ALS can be found in the radar freeboards from SIRAL and ASIRAS which serves as an additional mean of validation. Average snow depth estimates from OIB $(0.31 \pm 0.06 \mathrm{~m})$ and the W99 climato$\log y(0.36 \pm 0.09 \mathrm{~m})$ are comparable with the average ALS-ASIRAS freeboards $(0.44 \pm 0.14 \mathrm{~m})$, suggesting that a combination of laser and $\mathrm{Ku}$-band radar 
altimetry could be used to measure a layer of cold and dry snow. However, an assessment of the actual snow depth estimation capabilities of this method would require further validation which should include coincident snow depth estimates from snow radars and in-situ measurements.

A reduction in the radar freeboard uncertainty is observed for the SIN scenario compared to the $\mathrm{SIN}_{0}$ scenario. In general, one could say that the higher the number of processed waveforms, the lower the total random uncertainty of the estimates - a concept further supported by the study in Di Bella (2015). It is observed that including in the SIN scenario $\sim 35 \%$ of the waveforms discarded in the $\mathrm{SIN}_{0}$ scenario, reduces the uncertainty of $\sim 40 \%$ without introducing a bias on the average freeboard. These results suggest that by taking advantage of the SIRAL interferometric capabilities it is possible to significantly reduce the random part of the radar freeboard uncertainty. On the other hand, further investigation about the error sources affecting such estimates is necessary. In fact, the covariance of the individual error contributions is not taken into account in this work.

\section{Acknowledgements}

This work was supported by the project Space-borne observations for detecting and forecasting sea ice cover extremes (SPICES) funded mainly by the European Union's Horizon 2020 Programme. CryoSat-2 data and ASAR images were provided by the European Space Agency (ESA). The CryoVEx campaigns are part of ESA's Living Planet Programme and the airborne laser scanner data are provided by DTU Space. The ASIRAS data are part of the CryoVal-SI project and are provided by the Alfred Wagner Institute. The authors would like to thank Dr. Scagliola from ARESYS for valuable input during the project. 


\section{References}

Abulaitijiang, A., Andersen, O. B., Stenseng, L., 2015. Coastal sea level from inland CryoSat-2 interferometric SAR altimetry. Geophysical Research Letters 42 (6), 1841-1847.

Andersen, O. B., Stenseng, L., Piccioni, G., Knudsen, P., 2016. The DTU15 MSS (Mean Sea Surface) and DTU15LAT (Lowest Astronomical Tide) reference surface. Proceeding of the ESA Living Planet Symposium 2016.

Armitage, T. W. K., Davidson, M. W. J., 2014. Using the Interferometric Capabilities of the ESA CryoSat-2 Mission to Improve the Accuracy of Sea Ice Freeboard Retrievals. Ieee Transactions on Geoscience and Remote Sensing 52 (1), 529-536.

Comiso, J. C., 2012. Large decadal decline of the arctic multiyear ice cover. Journal of Climate 25 (4), 1176-1193.

Desch, S. J., Smith, N., Groppi, C., Vargas, P., Jackson, R., Kalyaan, A., Nguyen, P., Probst, L., Rubin, M. E., Singleton, H., Spacek, A., Truitt, A., Zaw, P. P., Hartnett, H. E., 2017. Arctic ice management. Earths Future 5 (1), 107-127.

Di Bella, A., 2015. Validation of CryoSat-2 SARIn Performance over Arctic Sea Ice. Master's thesis, Technical University of Denmark, http: //findit.dtu.dk/en/catalog/2346508692.

ESA, UCL, 2014. CryoSat Product Handbook. European Space Agency and University College London.

Galin, N., Wingham, D. J., Cullen, R., Fornari, M., Smith, W. H. F., Abdalla, S., 2013. Calibration of the CryoSat-2 Interferometer and Measurement of Across-Track Ocean Slope. Ieee Transactions on Geoscience and Remote Sensing 51 (1), 57-72.

Haas, C., Hendricks, S., Ricker, R., King, J., Beckers, J. Skourup, H., Farrell, S. L., Baker, S., Gaudelli, J., 2016. CryoVal-SI: CryoSat Sea Ice Product Validation using CryoVex and IceBridge campaign data. 1.1 Edition, Technical Note 3: Assessment of Different Sources of Uncertainty. Doc. No.: CVSI-TN-WP3-3001. 
Hvidegaard, S., Forsberg, R., 2002. Sea-ice thickness from airborne laser altimetry over the Arctic Ocean north of Greenland. Geophysical Research Letters 29 (20), 13-1 - 13-4.

Kildegaard Rose, S., 2013. Measurements of sea ice by satellite and airborne altimetry. Ph.D. thesis, DTU Space, http://orbit.dtu.dk/files/ 80537655/PhD_SKRose.pdf.

Kurtz, N., Studinger, M. S., Harbeck, J., Onana, V., Yi, D., 2015. IceBridge L4 Sea Ice Freeboard, Snow Depth, and Thickness, Version 1. Boulder, Colorado USA. NASA National Snow and Ice Data Center Distributed Active Archive Center.

Kurtz, N. T., Farrell, S. L., 2011. Large-scale surveys of snow depth on arctic sea ice from operation icebridge. Geophysical Research Letters 38 (20), $\mathrm{n} / \mathrm{a}-\mathrm{n} / \mathrm{a}, 120505$.

URL http://dx.doi.org/10.1029/2011GL049216

Kurtz, N. T., Galin, N., Studinger, M., 2014. An improved CryoSat-2 sea ice freeboard retrieval algorithm through the use of waveform fitting. Cryosphere 8 (4), 1217-1237.

Kwok, R., Cunningham, G. F., 2015. Variability of arctic sea ice thickness and volume from cryosat-2. Philosophical Transactions of the Royal Society A-mathematical Physical and Engineering Sciences 373 (2045), 0157.

Kwok, R., Cunningham, G. F., Wensnahan, M., Rigor, I., Zwally, H. J., Yi, D., 2009. Thinning and volume loss of the Arctic Ocean sea ice cover: 2003-2008. Journal of Geophysical Research - Part C - Oceans 114 (C7), C07005.

Kwok, R., Rothrock, D. A., 2009. Decline in Arctic sea ice thickness from submarine and ICESat records: 1958-2008. Geophysical Research Letters 36 (15), L15501.

Laxon, S., Peacock, N., Smith, D., 2003. High interannual variability of sea ice thickness in the arctic region. Nature 425 (6961), 947-950.

Laxon, S. W., Giles, K. A., Ridout, A. L., Wingham, D. J., Willatt, R., Cullen, R., Kwok, R., Schweiger, A., Zhang, J., Haas, C., Hendricks, S., 
Krishfield, R., Kurtz, N., Farrell, S., Davidson, M., 2013. CryoSat-2 estimates of Arctic sea ice thickness and volume. Geophysical Research Letters 40, 732-737.

Maslanik, J., Stroeve, J., Fowler, C., Emery, W., 2011. Distribution and trends in arctic sea ice age through spring 2011. Geophysical Research Letters 38 (13), L13502.

Newman, T., Farrell, S. L., Richter-Menge, J., Connor, L. N., Kurtz, N. T., Elder, B. C., McAdoo, D., 2014. Assessment of radar-derived snow depth over arctic sea ice. Journal of Geophysical Research-oceans 119 (12), 85788602.

Polyakov, I. V., Walsh, J. E., Kwok, R., 2012. Recent changes of arctic multiyear sea ice coverage and the likely causes. Bulletin of the American Meteorological Society 93 (2), 145-151.

Ricker, R., Hendricks, S., Helm, V., Skourup, H., Davidson, M., 2014. Sensitivity of CryoSat-2 Arctic sea-ice freeboard and thickness on radarwaveform interpretation. Cryosphere 8 (4), 1607-1622.

Skourup, H., Einarsson, I., Forsberg, R., Haas, C., Helms, V., Hvidegaard, S. M., Nilsson, J., Olesen, A. V., Olesen, A. K., 2012. ESA CryoVEx 2012.

Skourup, H., Farrell, S. L., Hendricks, S., Ricker, R., Armitage, T. W. K., Ridout, A., Andersen, O. B., Haas, C., Baker, S., 2017. An assessment of state-of-the-art mean sea surface and geoid models of the arctic ocean: Implications for sea ice freeboard retrieval. Journal of Geophysical Research: Oceans 122 (11), 8593-8613.

Stroeve, J. C., Serreze, M. C., Holland, M. M., Kay, J. E., Malanik, J., Barrett, A. P., 2012. The Arctic's rapidly shrinking sea ice cover: a research synthesis. Climatic Change 110 (3-4), 1005-1027.

Vignudelli, S., Kostianoy, A., Cipollini, P., Benveniste, J. (Eds.), 2011. Coastal Altimetry. Springer.

Warren, S., Rigor, I., Untersteiner, N., Radionov, V., Bryazgin, N., Aleksandrov, Y., Colony, R., 1999. Snow depth on arctic sea ice. Journal of Climate 12 (6), 1814-1829. 
Wingham, D., Francis, C., Baker, S., Bouzinac, C., Brockley, D., Cullen, R., de Chateau-Thierry, P., Laxon, S., Mallow, U., Mavrocordatos, C., Phalippou, L., Ratier, G., Rey, L., Rostan, F., Viau, P., Wallis, D., 2006. CryoSat: A mission to determine the fluctuations in Earths land and marine ice fields. Advances in Space Research 37 (4), 841 - 871, natural Hazards and Oceanographic Processes from Satellite Data.

Wingham, D., Phalippou, L., Mavrocordatos, C., Wallis, D., Oct 2004. The mean echo and echo cross product from a beamforming interferometric altimeter and their application to elevation measurement. IEEE Transactions on Geoscience and Remote Sensing 42 (10), 2305-2323. 